\title{
Light transfer in agar immobilized microalgae cell cultures
}

\author{
Razmig Kandilian ${ }^{\mathrm{a}, \mathrm{c}}$, Bruno Jesus ${ }^{\mathrm{b}}$, Jack Legrand ${ }^{\mathrm{a}}$, Laurent Pilon ${ }^{\mathrm{c}, *}$, Jérémy Pruvost ${ }^{\mathrm{a}, *}$ \\ a Université de Nantes, GEPEA, UMR-CNRS 6144, Bd de l'Université, CRTT-BP 406, 44602, Saint-Nazaire Cedex, France \\ ${ }^{\mathrm{b}}$ Laboratoire Mer Molécules Santé, EA2160, 2 rue de la Houssiniére, Université de Nantes, 44322 Nantes Cedex 3, France \\ ${ }^{\mathrm{c}}$ Mechanical and Aerospace Engineering Department, Henry Samueli School of Engineering and Applied Science, University of California, Los Angeles - Los \\ Angeles, CA 90095, USA
}

\begin{abstract}
A B S T R A C T
This paper experimentally and theoretically investigates light transfer in agar-immobilized cell cultures. Certain biotechnological applications such as production of metabolites secreted by photosynthetic microorganisms require cells to be immobilized in biopolymers to minimize contamination and to facilitate metabolite recovery. In such applications, light absorption by cells is one of the most important parameters affecting cell growth or metabolite productivity. Modeling light transfer therein can aid design and optimize immobilized-cell reactors. In this study, Parachlorella kessleri cells with areal biomass concentrations ranging from 0.36 to $16.9 \mathrm{~g} / \mathrm{m}^{2}$ were immobilized in $2.6 \mathrm{~mm}$ thick agar gels. The average absorption and scattering cross-sections as well as the scattering phase function of $P$. kessleri cells were measured. Then, the absorption and transport scattering coefficients of the agar gel were determined using an inverse method based on the modified two-flux approximation. The forward model was used to predict the normal-hemispherical transmittance and reflectance of the immobilized-cell films accounting for absorption and scattering by both microalgae and the agar gel. Good agreement was found between the measured and predicted normal-hemispherical transmittance and reflectance provided absorption and scattering by agar were taken into account. Moreover, good agreement was found between experimentally measured and predicted mean rate of photon absorption. Finally, optimal areal biomass concentration was determined to achieve complete absorption of the incident radiation.
\end{abstract}

\section{Introduction}

Photosynthetic microalgae, cyanobacteria, and diatoms have wide range of applications in the nutraceutical [1], cosmetics [2], pharmaceutical [3], biofuels [4], and food processing industries [5]. They are also used in tertiary wastewater treatment [6] and animal feed production [7]. These microorganisms are typically grown in open ponds or closed photobioreactors (PBRs) exposed to solar radiation or artificial illumination. Then, the cells are suspended in nutrient media by mechanical mixing using paddle wheels or by air $/ \mathrm{CO}_{2}$ mixture injection within the PBR suspension [8]. However, for certain biotechnological applications, such as wastewater treatment $[9,10]$ and secreted metabolite production [11,12], the use of immobilized-cell reactors are preferred. Then, metabolite production $[11,12]$ or pollutant consumption $[9,10]$ is favored instead of cell division.

\footnotetext{
* Corresponding authors.

E-mail addresses: pilon@seas.ucla.edu (L. Pilon), jeremy.pruvost@univ-nantes.fr (J. Pruvost).
}

Fig. 1 shows a schematic of an immobilized-cell PBR illustrating nutrient and metabolite exchange between cells immobilized in a biopolymer and the nutrient medium flowing above. In this configuration, the metabolites produced by the immobilized microorganisms diffuse out of the biopolymer into the growth medium while the nutrients consumed by the microorganisms diffuse into the biopolymer. This allows maintaining biomass in the culture system while facilitating the recovery of metabolites exuded by the cells [9]. Immobilization also minimizes biological contamination of the culture by creating a physical barrier for potential contaminants [13]. Finally, it prevents metabolite accumulation in the medium which may have toxic or inhibitory effects on productivity [11]. Two quintessential microorganisms ideal for immobilized cultivation are the microalgae Botryococcus braunii which secretes liquid hydrocarbons used for biofuel production [14] and the diatom Haslea ostrearia which exudes a blue pigment used in aquacultures and in the pharmaceutical industry [15].

Light absorption rate of the cells and light utilization efficiency of immobilized-cell PBRs are arguably the most important parameters affecting cell and/or metabolite productivity [16-22]. Thus, careful light transfer analysis must be conducted to optimize light 


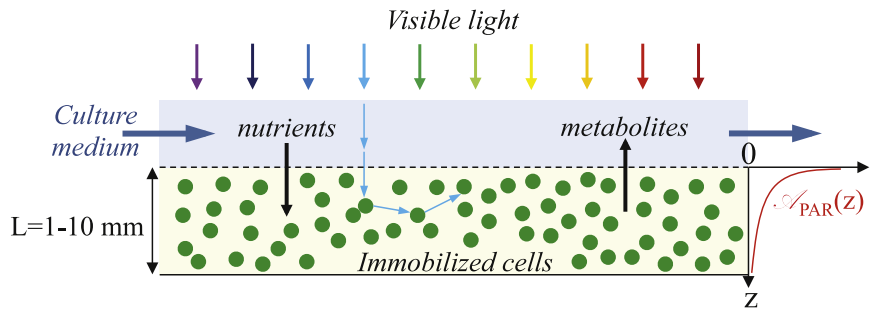

Fig. 1. Schematic of immobilized-cell PBR with nutrient medium flowing above immobilized cells suppling fresh nutrients and removing metabolites.

absorption rate by immobilized cells and to design and operate PBRs efficiently. Light transfer in PBRs containing cells suspended in liquid media has been extensively studied [22-25]. Methodologies have been developed to measure the radiation characteristics and determine the optical properties of free-floating microalgae and cyanobacteria $[23,25,26]$. Moreover, models of various complexity have been developed to predict the local fluence rate and the rate of energy absorption in open ponds, flat-plate, and cylindrical PBRs [24,27-31] and to predict transmittance and reflectance [32,33]. However, to the best of our knowledge no study has investigated light transfer in immobilized-cell films. It remains unclear whether models and methodologies developed for conventional PBRs with free-floating microorganisms are applicable to immobilized-cell PBRs given the presence of the immobilizing polymer and the lack of mixing.

This study aims to develop and experimentally validate a model predicting light transfer in immobilized-cell PBRs. Validation was performed with Parachlorella kessleri cells immobilized in agar gel. This study also reports the spectral radiation characteristics, over the photosynthetically active radiation (PAR) region, of the two constituents of the immobilized-cell film, namely, the photosynthetic cells and the agar gel. Finally, the results were used to define simple rules and strategies for optimizing productivity in lightlimited immobilized-cell films.

\section{Background}

\subsection{Modeling light transfer in PBRs}

The local and spectral specific rate of photon absorption (RPA), $\mathscr{A}_{\lambda}(\boldsymbol{r})\left(\mu \mathrm{mol}_{h v} / \mathrm{kg} \cdot \mathrm{s}\right)$ represents the number of photons of wavelength $\lambda$ absorbed per unit of dry biomass and per unit time at location $\boldsymbol{r}$ in the PBR [34]. It depends on the average mass absorption cross-section $\bar{A}_{a b s, \lambda}$ (in $\mathrm{m}^{2} / \mathrm{kg}$ ) of the microorganisms and on the local fluence rate $G_{\lambda}(\boldsymbol{r})$ (in $\mu \mathrm{mol}_{h v} / \mathrm{m}^{2} \cdot \mathrm{s}$ ) at location $\boldsymbol{r}$ and wavelength $\lambda$, according to [34]

$\mathscr{A}_{\lambda}(\boldsymbol{r})=\bar{A}_{a b s, \lambda} G_{\lambda}(\boldsymbol{r})$.

For absorbing and scattering media, such as microalgae suspensions, the local spectral fluence rate $G_{\lambda}(\boldsymbol{r})$ can be obtained by solving the radiative transfer equation [35]. Typically, the local PARaveraged fluence rate $G_{P A R}(\boldsymbol{r})$ and PAR-averaged RPA $\mathscr{A}_{\text {PAR }}(\boldsymbol{r})$ are used to model microalgae growth and productivity [22]. The PARaveraged fluence rate $G_{P A R}(\boldsymbol{r})$ can be expressed as [34]

$G_{P A R}(\boldsymbol{r})=\int_{400}^{700} G_{\lambda}(\boldsymbol{r}) \mathrm{d} \lambda$

Similarly, the local PAR-averaged rate of photon absorption $\mathscr{A}_{\text {PAR }}(\boldsymbol{r})$ can be defined as [34]

$\mathscr{A}_{P A R}(\boldsymbol{r})=\int_{400}^{700} \mathscr{A}_{\lambda}(\boldsymbol{r}) \mathrm{d} \lambda$
Finally, the volume-averaged RPA or the mean rate of photon absorption (MRPA) in a PBR of volume $V$ can be estimated according to [34]

$\left\langle\mathscr{A}_{P A R}\right\rangle=\frac{1}{V} \int_{V} \mathscr{A}_{\text {PAR }}(\boldsymbol{r}) \mathrm{d} V$

For flat-plate PBRs of thickness $L$ with transparent front $(z=0 \mathrm{~m})$ and back $(z=L)$ windows containing strongly forward scattering microalgae and exposed to normally incident spectral radiation flux $q_{i n, \lambda}^{\prime \prime}$, light transfer is one-dimensional and the local fluence rate $G_{\lambda}(z)$ can be predicted at depth $z$ by the two-flux approximation as [27]

$\frac{G_{\lambda}(z)}{\left(1-\rho_{1, \lambda}\right) q_{i n, \lambda}^{\prime \prime}}=2 \frac{\left(1+\alpha_{\lambda}\right) e^{\delta_{\lambda}(L-z)}-\left(1-\alpha_{\lambda}\right) e^{-\delta_{\lambda}(L-z)}}{\left(1+\alpha_{\lambda}\right)^{2} e^{\delta_{\lambda} L}-\left(1-\alpha_{\lambda}\right)^{2} e^{-\delta_{\lambda} L}}$

where the coefficients $\alpha_{\lambda}$ (unitless) and $\delta_{\lambda}$ (in $\mathrm{m}^{2} / \mathrm{kg}$ ) are expressed as [27]

$\alpha_{\lambda}=\sqrt{\frac{\kappa_{\lambda}}{\kappa_{\lambda}+2 b_{\lambda} \sigma_{s, \lambda}}}$ and $\delta_{\lambda}=\sqrt{\kappa_{\lambda}\left(\kappa_{\lambda}+2 b_{\lambda} \sigma_{s, \lambda}\right)}$.

Here, $\kappa_{\lambda}$ and $\sigma_{s, \lambda}$ are respectively the average absorption and single scattering coefficients and $b_{\lambda}$ is the average backward scattering fraction of the microalgae suspension [27]. In addition, $\rho_{1, \lambda}$ is the front surface normal-normal reflectivity given by Fresnel's equations. For an optically smooth agar film/air interface under normally incident radiation $\rho_{1, \lambda}$ can be expressed as [36]

$\rho_{1, \lambda}=\frac{\left(n_{m, \lambda}-1\right)^{2}}{\left(n_{m, \lambda}+1\right)^{2}}$.

where $n_{m, \lambda}$ is the growth medium refractive index. The two-flux approximation has been shown to give good predictions of the local fluence rate $G_{\lambda}(z)$ for flat-plate PBRs and open ponds $[27,30,34]$.

An alternative way of expressing the MRPA is by performing an energy balance on the incoming and outgoing radiation in a onedimensional PBR such that [37]

$\left\langle\mathscr{A}_{P A R}\right\rangle=\frac{1}{X L}\left[q_{P A R}^{\prime \prime}(0)-q_{P A R}^{\prime \prime}(L)\right]=\frac{q_{P A R, i n}^{\prime \prime}}{X L} \Gamma$

where $q_{P A R}^{\prime \prime}(0)$ and $q_{P A R}^{\prime \prime}(L)$ are the PAR-averaged radiation flux at the front and back of the PBR, respectively. Similarly, $q_{P A R, i n}^{\prime \prime}$ is the incident photon flux density averaged over the PAR region expressed in $\mu \mathrm{mol}_{h v} / \mathrm{m}^{2}$.s. Moreover, $\Gamma$ is the fraction of light absorbed by the microalgae over the PAR region estimated as

$\Gamma=\frac{1}{\left(\lambda_{\max }-\lambda_{\min }\right)} \int_{\lambda_{\min }}^{\lambda_{\max }}\left(1-T_{n h, \lambda}-R_{n h, \lambda}\right) \mathrm{d} \lambda$.

Here, $T_{n h, \lambda}$ and $R_{n h, \lambda}$ are respectively the normal-hemispherical spectral transmittance and reflectance of the immobilized-cell films while integration is performed over the PAR region such that $\lambda_{\text {min }}=400 \mathrm{~nm}$ and $\lambda_{\max }=700 \mathrm{~nm}$.

Finally, Cornet and co-workers $[16,17,19,38,39]$ have developed a kinetic model that can predict microalgae growth and productivity based on the local RPA $\mathscr{A}_{\text {PAR }}(\boldsymbol{r})$. The model predicts both the local rate of oxygen production and the local biomass productivity. The authors reported that the maximum productivity of a PBR occurs when the minimum PAR-averaged local RPA in the PBR is equal to the so-called photosynthesis compensation point $\mathscr{A}_{c}$. In a flat-plate PBR of thickness $L$ illuminated from one side $(z=0 \mathrm{~m})$, the minimum RPA occurs at the back wall of the PBR, i.e., at $z=L$. Note that the photosynthesis compensation point $\mathscr{A}_{c}$ depends on the microorganism species. For example, it was reported to be around $1500 \mu \mathrm{mol}_{h v} / \mathrm{kg}$.s for Chlorella vulgaris [39]. 


\subsection{Normal-hemispherical reflectance and transmittance}

Let us consider a homogeneous absorbing, scattering, but nonemitting slab of immobilized-cell film of thickness $L$ exposed to collimated and normally incident radiation on one side. Radiation transfer in this case can be assumed to be one-dimensional $[28,30]$. The slab or film is assumed to be reflecting and refracting and subject to internal reflection. Solving the radiation transfer equation based on the modified two-flux approximation and the transport approximation leads to an analytical expression for the spectral normal-hemispherical transmittance $T_{n h, \lambda \text {,pred }}$ and reflectance $R_{n h, \lambda, \text { pred }}$ given by [36]

$T_{n h, \lambda, \text { pred }}=T_{n h, \lambda}^{0}+\frac{D_{\lambda}}{2}\left[\left(1+\rho_{1, \lambda}\right) \exp \left(-\tau_{t r, \lambda, L}\right)+A_{\lambda} / \zeta_{\lambda}\right]$

and

$$
R_{n h, \lambda, p r e d}=R_{n h, \lambda}^{0}+\frac{D_{\lambda}}{2}\left(1+B_{\lambda} / \zeta_{\lambda}+C_{t r, \lambda}\right)
$$

where $\tau_{t r, \lambda, L}$ is the transport optical thickness defined as $\tau_{t r, \lambda, L}=$ $\beta_{t r, \lambda} L$ where $\beta_{t r, \lambda}$ is the transport extinction coefficient of the immobilized-cell film. Here, $T_{n h, \lambda}^{0}$ and $R_{n h, \lambda}^{0}$ are respectively the spectral normal-hemispherical transmittance and reflectance ignoring multiple scattering and expressed as [40]

$R_{n h, \lambda}^{0}=\frac{\rho_{1, \lambda}+\left(1-\rho_{1, \lambda}\right)^{2} C_{t r, \lambda}}{1-\rho_{1, \lambda} C_{t r, \lambda}} \quad$ and $\quad T_{n h, \lambda}^{0}=\frac{\left(1-\rho_{1, \lambda}\right)^{2}}{1-\rho_{1, \lambda} C_{t r, \lambda}} e^{-\tau_{t r, \lambda, L}}$

The parameters $A_{\lambda}, B_{\lambda}, C_{t r, \lambda}, D_{\lambda}$, and $\zeta_{\lambda}$ are intermediary variables defined in Refs. [33,36].

The two-flux approximation has often been used to predict onedimensional radiation transfer in plane-parallel absorbing, emitting, and/or isotropically scattering slabs [40]. On the other hand, the modified two-flux approximation derived by Dombrovsky et al. [36] (i) takes into account internal reflection in the slab and (ii) uses the transport approximation to account for anisotropic scattering. The modified two-flux approximation has been validated against predictions by the discrete ordinate method for strongly forward scattering media [36] and successfully applied to glass containing bubbles [36] and microalgae cultures [33].

\subsection{Determination of radiation characteristics}

The size-averaged spectral mass absorption and scattering cross-sections $\bar{A}_{a b s, \lambda}$ and $\bar{S}_{s c a, \lambda}$ of free-floating microalgae can be experimentally measured according to a procedure reviewed by Pilon et al. $[23,25]$. In this method, the normal-normal $T_{n n, \lambda}$ and normal-hemispherical $T_{n h, \lambda}$ transmittance of dilute microalgae suspensions of known concentrations are measured using a spectrophotometer without and with an integrating sphere, respectively. The pathlength of the cuvette and/or the microalgae concentration $X$ must be chosen such that single scattering prevails, i.e., photons undergo at most one scattering event when they travel through the suspension. In practice, the cuvette pathlength should be smaller than the photon mean-free path in order to obtain the average mass absorption $\bar{A}_{a b s, \lambda}$ and scattering $\bar{S}_{s c a, \lambda}$ cross-sections that are independent of concentration $X$.

The present study directly compares the measured normalhemispherical transmittance and reflectance of films consisting of P. kessleri cells immobilized in agar gel with predictions by the modified two-flux approximation previously discussed. It also reports direct measurements of the radiation characteristics of $P$. kessleri in suspension as well as the absorption and transport scattering coefficients of the agar gel alone retrieved from normalhemispherical transmittance and reflectance measurements. Finally, guidelines for optimizing immobilized-cell PBRs with respect to the incident irradiance are presented.

\section{Materials and methods}

\subsection{Species and culture medium}

The microalgae Parachlorella kessleri (UTEX2229) was obtained from the University of Texas Austin (UTEX) collection. It was cultivated in a modified Bold Basal medium with the following composition (in mM) $\mathrm{NaNO}_{3} 8.02, \mathrm{Na}_{2}$ EDTA $\cdot 2 \mathrm{H}_{2} \mathrm{O} 0.122, \mathrm{MgSO}_{4}$. $7 \mathrm{H}_{2} \mathrm{O} 0.83, \mathrm{~K}_{2} \mathrm{HPO}_{4} 0.78, \mathrm{KH}_{2} \mathrm{PO}_{4} 0.88, \mathrm{CaCl}_{2} \cdot 2 \mathrm{H}_{2} \mathrm{O} 0.155, \mathrm{FeSO}_{4}$. $7 \mathrm{H}_{2} \mathrm{O} 0.046, \mathrm{ZnSO}_{4} \cdot 7 \mathrm{H}_{2} \mathrm{O} 7.72 \times 10^{-4}, \mathrm{CuSO}_{4} 4.95 \times 10^{-4}, \mathrm{MnCl}_{2}$. $4 \mathrm{H}_{2} \mathrm{O} 9.15 \times 10^{-3}, \mathrm{H}_{3} \mathrm{BO}_{3} 4.63 \times 10^{-2}, \mathrm{Co}\left(\mathrm{NO}_{3}\right)_{2} \cdot 6 \mathrm{H}_{2} \mathrm{O} 1.51 \times 10^{-4}$, $\mathrm{Na}_{2} \mathrm{MoO}_{4} 1.06 \times 10^{-3}$, and $\mathrm{NaHCO}_{3}$ 1.5. The medium was sterilized by autoclaving at $121{ }^{\circ} \mathrm{C}$ for $25 \mathrm{~min}$. The microalgae were cultivated in a $1 l$ airlift PBR operated in continuous mode and previously described in detail in Refs. [18,20]. The dilution rate and the photon flux density were set to $0.011 / \mathrm{h}$ and $150 \mu \mathrm{mol}_{h v} / \mathrm{m}^{2} \cdot \mathrm{s}$, respectively. The culture medium $\mathrm{pH}$ was continuously monitored using a pH sensor (Mettler Toledo SG 3253) and was maintained at 8 by automatic injection of gaseous $\mathrm{CO}_{2}$ when the pH exceeded 8 . The culture under steady-state continuous operation achieved a dry biomass concentration $X$ of $1.6 \mathrm{~g} / \mathrm{l}$. To obtain samples with larger biomass concentrations, the harvested culture was centrifuged at 10,000g (ThermoScientific Sorvall RC 6 Plus, Massachusetts, USA) for $10 \mathrm{~min}$ at $4{ }^{\circ} \mathrm{C}$ and suspended in phosphate buffer saline (PBS) solution.

\subsection{Biomass and pigment concentrations}

Microorganism dry biomass concentration $X$ (in $\mathrm{kg} / \mathrm{m}^{3}$ ) was measured gravimetrically by filtering $5 \mathrm{ml}$ of the continuous airlift PBR culture through a pre-dried and pre-weighed $0.45 \mu \mathrm{m}$ pore size glass-microfiber filter (Whatman GF/F). The filters were dried for a minimum of $24 \mathrm{~h}$ in an oven at $105{ }^{\circ} \mathrm{C}$ and weighed after being cooled in a desiccator for $30 \mathrm{~min}$. Each sample was analyzed in triplicates and the mean value of the biomass concentration was reported.

Photosynthetic pigments were extracted in pure methanol and quantified spectrophotometrically. A volume of $0.5 \mathrm{ml}$ of the continuous airlift PBR culture was first centrifuged at 13,400 rpm $(12,100 \mathrm{~g})$ for $10 \mathrm{~min}$. The medium was discarded and the cells were resuspended in $1.5 \mathrm{ml}$ of pure methanol and sonicated for $20 \mathrm{~s}$. The samples were left for $1 \mathrm{~h}$ in an oven at $44{ }^{\circ} \mathrm{C}$ and the extract was then centrifuged. The optical density $\mathrm{OD}_{\lambda}$ of the supernatant was measured at wavelengths $\lambda$ equal to $750,665,652$, and $480 \mathrm{~nm}$ using a UV-vis spectrophotometer (Jasco V-730 Easton, MD). All extractions were performed in triplicates. Chlorophyll $a$ and $b$ concentrations, respectively denoted by $C_{C h l a}$ and $C_{C h l b}$, were estimated according to the correlations [41]

$C_{\text {Chla }}[m g / l]=-8.0962\left(O D_{652}-O D_{750}\right)+16.5169\left(O D_{665}-O D_{750}\right)$

$C_{C h l b}[m g / l]=27.4405\left(O D_{652}-O D_{750}\right)-12.1688\left(O D_{665}-O D_{750}\right)$.

Similarly, the total carotenoid concentration $C_{P P C}+P S C$, accounting for both photoprotective (PPC) and photosynthetic (PSC) carotenoids, was estimated according to [42]

$C_{P P C+P S C}[m g / l]=4\left(O D_{480}-O D_{750}\right)$.

\subsection{Microalgae radiation characteristics measurements}

The total scattering phase function $\Phi_{T, \lambda}(\Theta)$ of the free-floating microalgae was measured at $632.8 \mathrm{~nm}$ by a polar nephelometer described in Ref. [43]. It was assumed to be independent of wavelength over the PAR region. Due to interference of the probe with the laser beam, the scattering phase function could not be measured beyond $160^{\circ}$ with respect to the forward direction. This had 
no significant impact as the microalgae were much larger than the wavelength and scattering was strongly in the forward direction $[25,26,32,43]$.

The normal-normal transmittance $T_{n n, \lambda}$ measurements were performed using a UV-vis-NIR spectrophotometer (Agilent Cary 5000, Santa Clara, CA). The normal-hemispherical transmittance $T_{n h, \lambda}$ measurements were performed using the same spectrophotometer with an integrating sphere attachment (Agilent Cary DRA2500, Santa Clara, CA). The microalgae suspensions were centrifuged at $13,400 \mathrm{rpm}(12,100 \mathrm{~g})$ for $10 \mathrm{~min}$ and washed with PBS solution and resuspended in PBS to avoid absorption and scattering by the growth medium. The measurements were performed in $1 \mathrm{~cm}$ pathlength quartz cuvettes (110-10-40 Hellma Analytics, Müllheim, Germany) in the wavelength range from 350 to $750 \mathrm{~nm}$. The average spectral absorption $\bar{A}_{a b s, \lambda}$ and scattering $\bar{S}_{s c a, \lambda}$ crosssections of microalgae suspensions were measured for three sufficiently diluted biomass concentrations $X$, namely $0.041,0.048$, and $0.061 \mathrm{~m}^{2} / \mathrm{kg}$ to ensure that single scattering prevailed and that the retrieved $\bar{A}_{a b s, \lambda}$ and $\bar{S}_{s c a, \lambda}$ were independent of $X$ [44]. The crosssections reported correspond to the mean of the three measurements and the error bars correspond to 95\% confidence interval.

\subsection{Transmittance and reflectance of agar-immobilized cells}

\subsubsection{Sample preparation}

First, a $4 \%$ agar solution was prepared by mixing $10 \mathrm{~g}$ of bacteriological agar (Type A Biokar A1010) with $250 \mathrm{ml}$ of PBS. The solution was autoclaved at $121{ }^{\circ} \mathrm{C}$ for $20 \mathrm{~min}$ to melt and sterilize the agar. The mixture was then allowed to cool to $60{ }^{\circ} \mathrm{C}$ before adding the microalgae suspension to prevent cell death. Note that agar solidifies at $35-40{ }^{\circ} \mathrm{C}[45]$ and the microorganisms chosen for immobilization must be tolerant to temporary thermal shocks. Chlorella and Parachlorella, Dunaliella, Nannochloropsis, and Tetraselmis are examples of species tolerant to thermal shocks [45]. To immobilize $P$. kessleri cells in agar, $25 \mathrm{ml}$ of the warm agar solution was mixed with $15 \mathrm{ml}$ of microalgae suspension in PBS at room temperature such that the final concentration of agar in the mixture was 3.2 dry wt.\%. A total volume of $15 \mathrm{ml}$ of the agar/microalgae mixtures were poured into polystyrene petri dishes, $35 \mathrm{~mm}$ in diameter, immediately after mixing. Finally, the immobilized-cell films were allowed to cool to room temperature and form gels with effective thickness $L$ of $2.6 \mathrm{~mm}$. The biomass concentration of the microalgae suspensions was chosen such that the final biomass concentrations $X$ of the immobilized-cell films were 0.0, 0.139, 0.281, 0.559, 0.975, 4.35, and $6.49 \mathrm{~kg} / \mathrm{m}^{3}$. These corresponded to areal biomass concentrations $X L$ of $0.0,0.36,0.73,1.45,2.54,11.3$, and $16.9 \mathrm{~g} / \mathrm{m}^{2}$. The film corresponding to $X L=0 \mathrm{~g} / \mathrm{m}^{2}$ was prepared in an identical manner to those used for immobilizing the microalgae but only with PBS instead of the microalgae suspension. Moreover, the samples were concentrated by centrifuging $10-100 \mathrm{ml}$ of culture, corresponding to the desired final concentration of the sample, and re-suspending them in $15 \mathrm{ml}$ of PBS. They were not prepared by concentrating the entire culture and serially diluting it to obtain the desired sample concentration.

\subsubsection{Transmittance and reflectance measurements}

A cylindrical template with sharp edges was used to cut a circular disc of $2 \mathrm{~cm}$ in diameter out of the agar-immobilized P. kessleri samples (Fig. 2a). The normal-hemispherical transmittance $T_{n h, \lambda}$ and reflectance $R_{n h, \lambda}$ of the immobilized-cell films were systematically measured using the previously described apparatus. The samples were held in place using the solid sample holder accessory placed in front or behind the integrating sphere. Note that despite the relatively large concentration of agar in the samples (3.2 dry wt.\%), the cut out discs were fragile and had to be handled with care to prevent tearing.

\subsection{Inverse method}

The inverse method, previously developed by Kandilian et al. [33], was used to simultaneously retrieve the absorption $\kappa_{a, \lambda}$ and transport scattering $\sigma_{t r a, \lambda}=\left(1-g_{a, \lambda}\right) \sigma_{s, a, \lambda}$ coefficients of the agar gel alone using the measured normal-hemispherical transmittance $T_{n h, \lambda}$ and reflectance $R_{n h, \lambda}$ between the wavelengths of 350 and $750 \mathrm{~nm}$. The objective was to find the values of $\kappa_{a, \lambda}$ and $\sigma_{s, t r a, \lambda}$ that minimize the difference between the predicted [Eqs. (10)-(12)] and the experimentally measured spectral normalhemispherical transmittance and reflectance of the agar gel. For each wavelength, the objective function $\Delta_{\lambda}$ was defined as,

$\Delta_{\lambda}=\left(\frac{T_{n h, \lambda, \text { pred }}-T_{n h, \lambda}}{T_{n h, \lambda}}\right)^{2}+\left(\frac{R_{n h, \lambda, \text { pred }}-R_{n h, \lambda}}{R_{n h, \lambda}}\right)^{2}$.

Here, the inverse method to retrieve $\kappa_{a, \lambda}$ and $\sigma_{s, t r a, \lambda}$ was implemented in Microsoft Excel using the built-in non-linear solver based on the generalized reduced gradient (GRG) algorithm [46].

\subsection{Data analysis}

In order to predict the normal-hemispherical transmittance $T_{n h, \lambda, \text { pred }}$ and reflectance $R_{n h, \lambda \text {,pred }}$ using Eqs. (10)- (12), one needs to know (i) the thickness $L$ of the immobilized-cell film, (ii) the effective refractive index of the medium $n_{m, \lambda}$, (iii) the absorption coefficient $\kappa_{\lambda}$, and (iv) the transport scattering coefficient $\sigma_{s, t r, \lambda}=$ $\sigma_{s, \lambda}\left(1-g_{\lambda}\right)$ of the immobilized-cell film. Here, the index of refraction of the agar medium was assumed to be equal to that of PBS whose spectral refractive index can be expressed by the Cauchy dispersion relation [47]

$n_{m, \lambda}=1.32711+\frac{0.0026}{\lambda^{2}}+\frac{0.00005}{\lambda^{4}}$

where the wavelength $\lambda$ is expressed in $\mu \mathrm{m}$ in the range from 0.37 to $1.610 \mu \mathrm{m}$. Moreover, PBS can be safely treated as non-absorbing in the visible part of the spectrum [47].

Moreover, absorption and scattering by the agar matrix must be accounted for when predicting normal-hemispherical transmittance $T_{n h, \lambda}$ and reflectance $R_{n h, \lambda}$ of the immobilized-cell films. Here, the absorption $\kappa_{\lambda}$ and scattering $\sigma_{s, \lambda}$ coefficients (in $1 / \mathrm{m}$ ) of the immobilized-cell films were expressed as the sum of the respective contributions of the agar matrix and of the microalgae cells of concentration $X$ so that

$$
\begin{aligned}
\kappa_{\lambda} & =\kappa_{\mu, \lambda}+\kappa_{a, \lambda}=\bar{A}_{a b s, \lambda} X+\kappa_{a, \lambda} \text { and } \\
\sigma_{s, \lambda} & =\sigma_{s, \mu, \lambda}+\sigma_{s, a, \lambda}=\bar{S}_{s c a, \lambda} X+\sigma_{s, a, \lambda}
\end{aligned}
$$

where $\kappa_{\mu, \lambda}=\bar{A}_{a b s, \lambda} X$ and $\sigma_{s, \mu, \lambda}=\bar{S}_{s c a, \lambda} X$ are respectively the average absorption and single scattering coefficients of randomly oriented microalgae in PBS while $\bar{A}_{a b s, \lambda}$ and $\bar{S}_{s c a, \lambda}$ are the average spectral mass absorption and scattering cross-sections (in $\mathrm{m}^{2} / \mathrm{kg}$ ). Similarly, the transport scattering coefficient of the immobilizedcell films was expressed as

$\sigma_{s, t r, \lambda}=\bar{S}_{s c a, \lambda} X\left(1-g_{\mu, \lambda}\right)+\sigma_{s, a, \lambda}\left(1-g_{a, \lambda}\right)$

where $g_{\mu, \lambda}$ and $g_{a, \lambda}$ are the asymmetry factors of the microalgae and of the agar gel, respectively.

Finally, the two-flux approximation for predicting the fluence rate $G_{\lambda}(z)$ in flat-plate PBRs [Eqs. (5) and (6)] can be applied to immobilized-cell films by expressing the backward scattering coefficient $b_{\lambda} \sigma_{s, \lambda}$ of the film as

$b_{\lambda} \sigma_{s, \lambda}=b_{\mu, \lambda} \sigma_{s, \mu, \lambda}+b_{a, \lambda} \sigma_{s, a, \lambda}$.

Here, backward scattering can be neglected in Eq. (6) compared with absorption, (i.e., $\kappa_{\lambda}>>2 b_{\lambda} \sigma_{s, \lambda}$ ) leading to $\alpha_{\lambda}=1$ and $\delta_{\lambda}=\kappa_{\lambda}$, as established in Refs. [21,33]. 
(a)

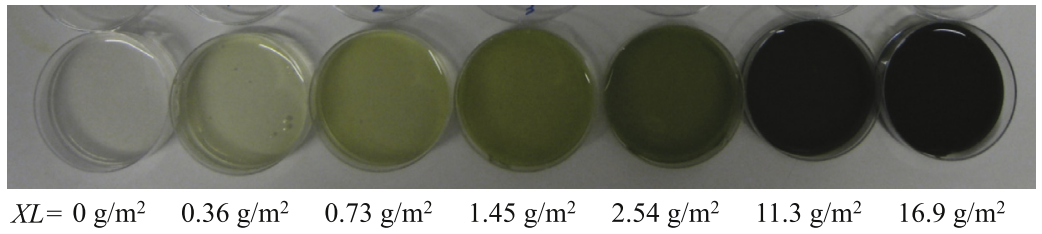

(b)

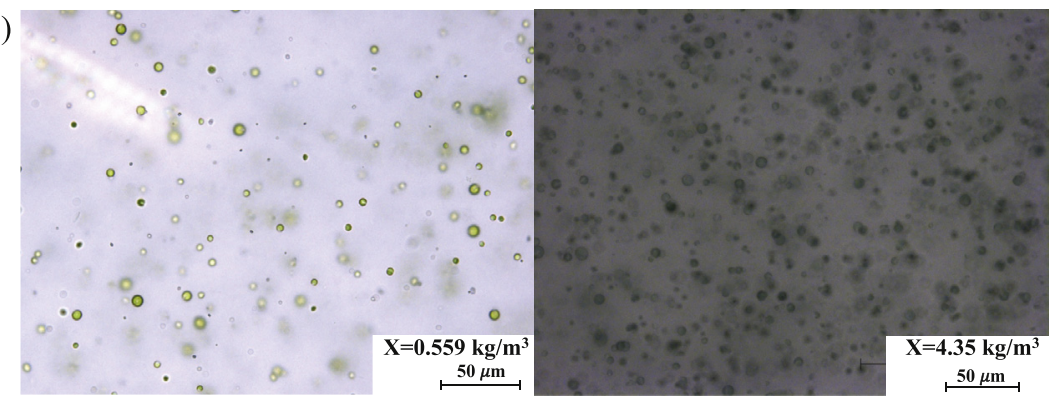

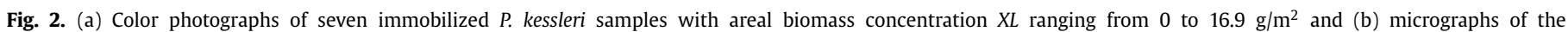
immobilized-cell films with biomass concentration $X$ equal to 0.559 and $4.35 \mathrm{~kg} / \mathrm{m}^{3}$.

\section{Results and discussion}

\subsection{Biomass and pigment concentration of immobilized-cell films}

Fig. 2a presents a photograph of seven agar-immobilized $P$. kessleri samples with areal biomass concentration $X L$ ranging from 0 to $16.9 \mathrm{~g} / \mathrm{m}^{2}$. Moreover, Fig. 2b shows micrographs of the immobilized cells for biomass concentrations of $0.559 \mathrm{~kg} / \mathrm{m}^{3}$ and $4.35 \mathrm{~kg} / \mathrm{m}^{3}$. It shows relatively loose packing of the cells in both low and high concentration samples. In fact, Souliés et al. [48] reported that the volume fraction of Chlorella vulgaris, a green microalgae similar in size to Parachlorella kessleri, was $1.6 \%$ when the biomass concentration $X$ of the culture was equal to $4 \mathrm{~kg} / \mathrm{m}^{3}$.

The concentrations of Chl $a$, Chl $b$, and total carotenoids of $P$. kessleri grown in the continuous airlift PBR were measured spectrophotometrically and found to be $C_{\text {Chla }}=46.8 \pm 1.41 \mathrm{mg} / l, C_{C h l b}$ $=13.0 \pm 0.62 \mathrm{mg} / l, C_{P P C+P S C}=12.0 \pm 0.29 \mathrm{mg} / \mathrm{l}$. These corresponded to mass fractions of $w_{\text {Chla }}=4.81 \pm 0.15 \mathrm{wt} . \%, w_{\text {Chlb }}=1.33$ \pm 0.06 wt.\%, and $w_{P P C+P S C}=1.24 \pm 0.03$ wt.\%.

\subsection{Radiation characteristics of microalgae cells}

Fig. 3a plots the experimentally measured scattering phase function of P. kessleri at $632.8 \mathrm{~nm}$. As expected, the microalgae cells scattered light strongly in the forward direction with asymmetry factor $g_{\mu, 633}$ and back-scattered fraction $b_{\mu, 633}$ corresponding to 0.974 and 0.0042 , respectively. Moreover, Figs. $3 \mathrm{~b}$ and $3 \mathrm{c}$ plot the average mass absorption $\bar{A}_{a b s, \lambda}$ and scattering $\bar{S}_{s c a, \lambda}$ cross-sections (in $\mathrm{m}^{2} / \mathrm{kg}$ ) the microalgae suspended in PBS solution measured between 350 and $750 \mathrm{~nm}$. Fig. 3b features absorption peaks corresponding to Chl $a$ at 435, 630, and $676 \mathrm{~nm}$. Similarly, the shoulder from 455 to $485 \mathrm{~nm}$ was due to the superposition of Chl $b$ absorption peak at $475 \mathrm{~nm}$ and that of PPC around 462 and $490 \mathrm{~nm}$ [49]. A second absorption peak of $\mathrm{Chl} b$ appeared also around $650 \mathrm{~nm}$. In addition, Figs. $3 \mathrm{~b}$ and $3 \mathrm{c}$ indicate that the microalgae scattering cross-section $\bar{S}_{s c a, \lambda}$ was significantly larger than their absorption cross-section $\bar{A}_{a b s, \lambda}$. However, Fig. 3d shows that transport scattering cross-section $\bar{S}_{s c a, t r, \lambda}=\bar{S}_{s c a, \lambda}\left(1-g_{\mu, \lambda}\right)$ was much smaller than the absorption cross-section of the microalgae at all wavelengths considered since $g_{\mu, \lambda}$ approached unity. These results were in qualitative and quantitative agreement with the radiation characteristics of microalgae with similar size and pigment concentrations $[26,32]$. Note that the reported absorption $\bar{A}_{a b s, \lambda}$ and scattering
$\bar{S}_{s c a, \lambda}$ cross-sections were the mathematical mean of samples with three different biomass concentrations and the error bars corresponded to $95 \%$ confidence intervals. These error bars were significantly smaller than the magnitudes of $\bar{A}_{a b s, \lambda}$ or $\bar{S}_{s c a, \lambda}$ indicating that absorption and scattering coefficients were directly proportional to the biomass concentration. This satisfied van de Hulst's simple and conclusive test for the absence of multiple scattering [44].

\subsection{Transmittance and reflectance of immobilized-cell films}

Figs. 4a and 4b plot the experimentally measured normalhemispherical transmittance $T_{n h, \lambda}$ and reflectance $R_{n h, \lambda}$ of $2.6 \mathrm{~mm}$ thick immobilized-cell films as functions of wavelength between 350 and $750 \mathrm{~nm}$ for $P$. kessleri biomass concentration $X$ ranging from 0 to $16.9 \mathrm{~g} / \mathrm{m}^{2}$. First, the normal-hemispherical transmittance $T_{n h, \lambda}$ of agar gel with PBS $\left(X L=0 \mathrm{~g} / \mathrm{m}^{2}\right)$ increased monotonously with increasing wavelength between 350 and $750 \mathrm{~nm}$. By contrast, the corresponding normal-hemispherical reflectance $R_{n h, \lambda}$ decreased from $9.7 \%$ at $350 \mathrm{~nm}$ to $1.9 \%$ at $750 \mathrm{~nm}$. Moreover, the normal-hemispherical transmittance $T_{n h, \lambda}$ decreased as the areal biomass concentration increased due to absorption by the immobilized microalgae. Similarly, the normal-hemispherical reflectance $R_{n h, \lambda}$ of the film decreased with increasing concentration in the PAR region ( $400 \leq \lambda \leq 700 \mathrm{~nm}$ ). However, $R_{n h, \lambda}$ increased with increasing values of $X L$ for wavelengths larger than $700 \mathrm{~nm}$. This was due to backscattering by the microalgae cells and to the fact that agar and microalgae are weakly or non-absorbing at these wavelengths.

\subsection{Remote immobilized-cell film PBR monitoring}

Fig. 5 plots the normal-hemispherical reflectance $R_{n h, 750}$ of the immobilized-cell films at $750 \mathrm{~nm}$ as a function of areal biomass concentration $X L$. The wavelength $\lambda=750 \mathrm{~nm}$ was chosen on the basis that green microalgae and cyanobacteria are non-absorbing at this wavelength and measurements of normal-hemispherical reflectance $R_{n h, 750}$ are not sensitive to variation in pigment concentration. Fig. 5 establishes that $R_{n h, 750}$ was linearly proportional to $X L$ leading to a least square fit of

$R_{n h, 750}(X L)=R_{n h, a, 750}+\epsilon X L$

where the coefficient of proportionality $\epsilon$ was equal to $5.5 \times 10^{-3}$ $\pm 3.1 \times 10^{-4} \mathrm{~m}^{2} / \mathrm{kg}$ while $R_{n h, a, 750}$ was the normal-hemispherical 
(a)

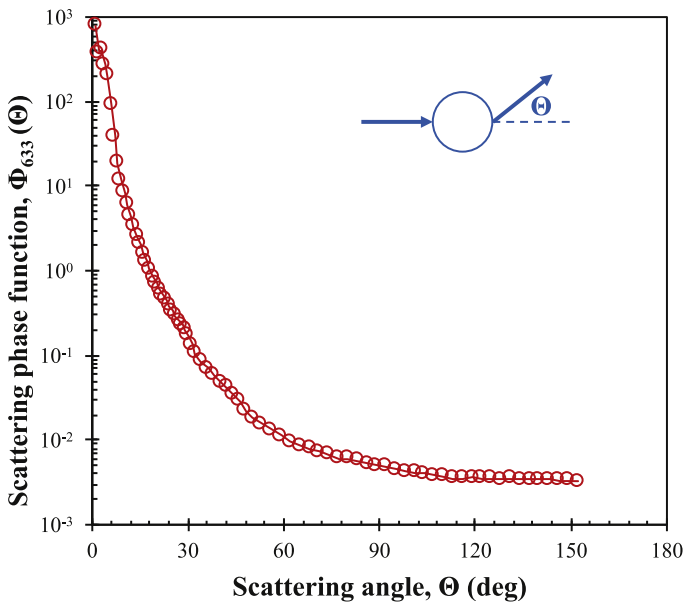

(c)

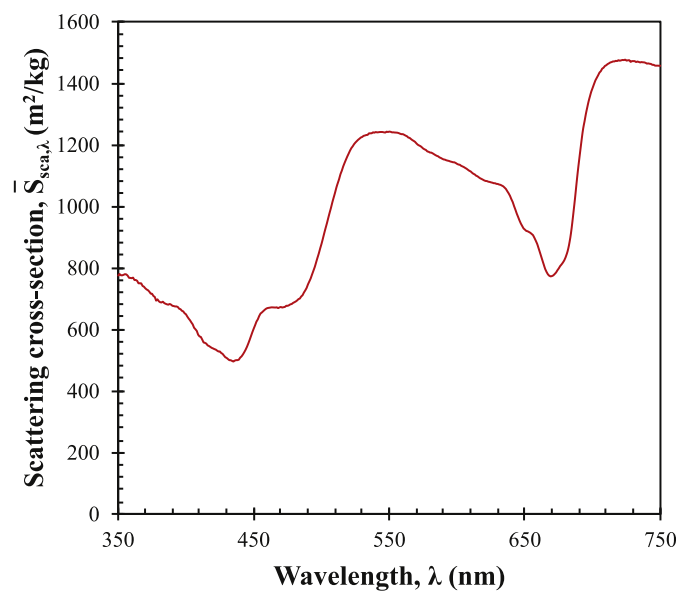

(b)

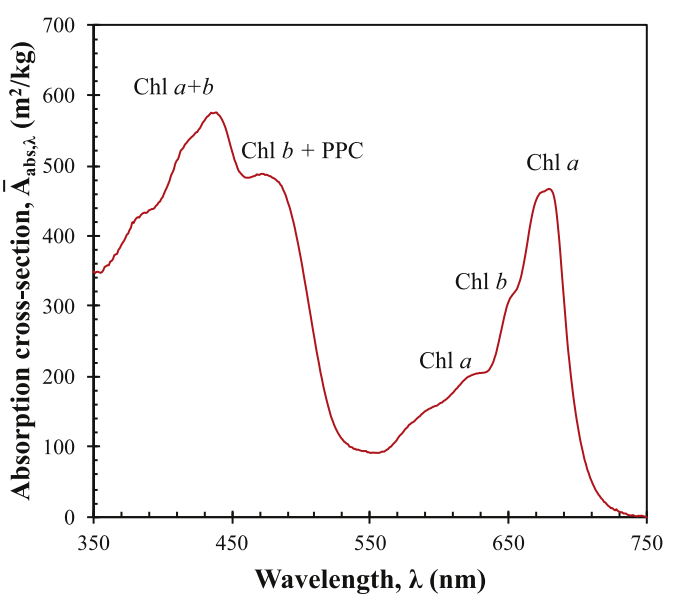

(d)

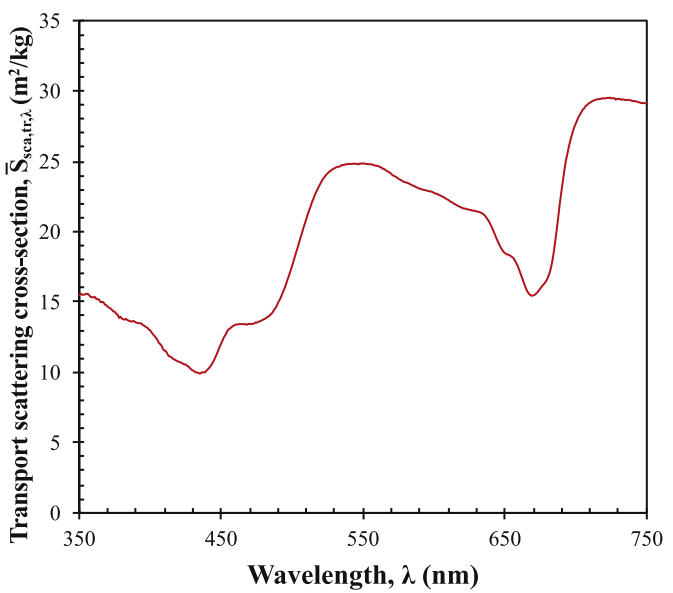

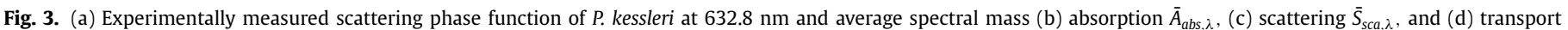
scattering $\bar{S}_{\text {sca,tr, } \lambda}$ cross-sections of $P$. kessleri suspensions between 350 and $750 \mathrm{~nm}$. Note that error bars were smaller than the symbols or lines.

(a)

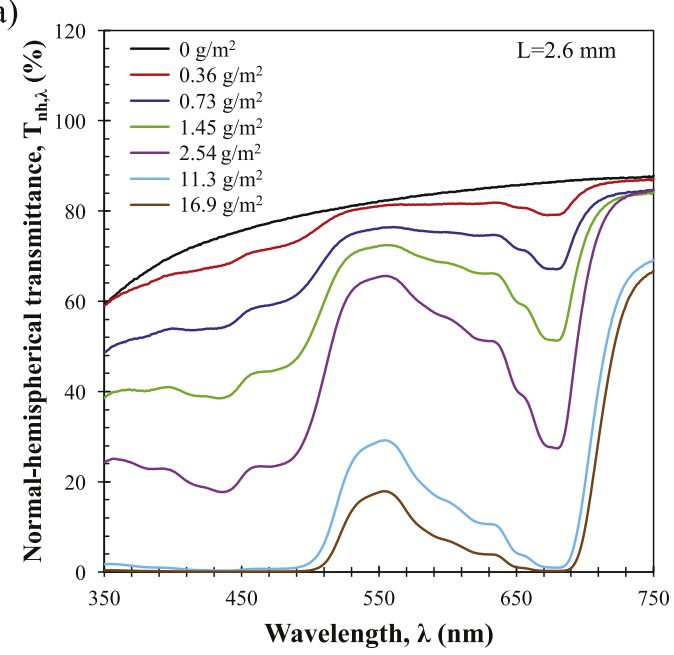

(b)

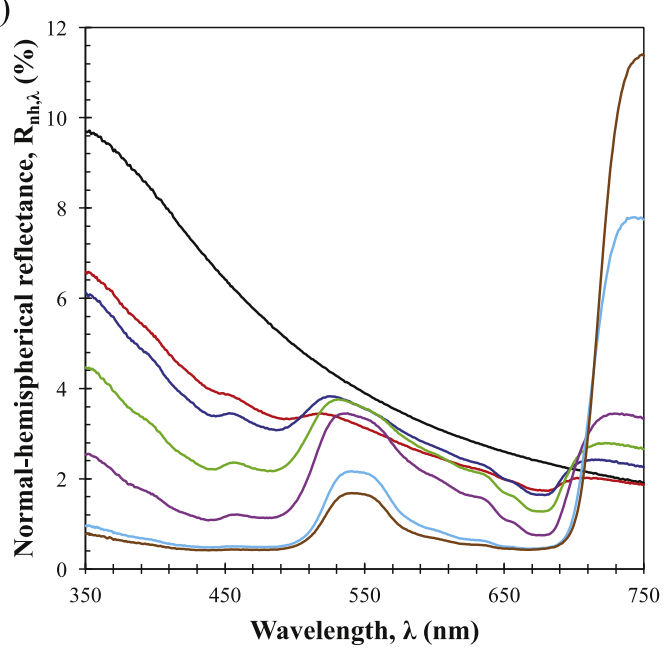

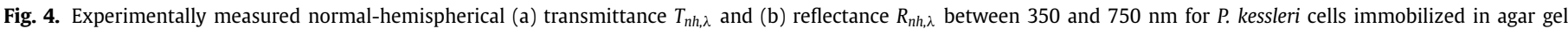
with thickness $L$ of $2.6 \mathrm{~mm}$ and areal biomass concentration $X L$ ranging from 0 to $16.9 \mathrm{~g} / \mathrm{m}^{2}$. 


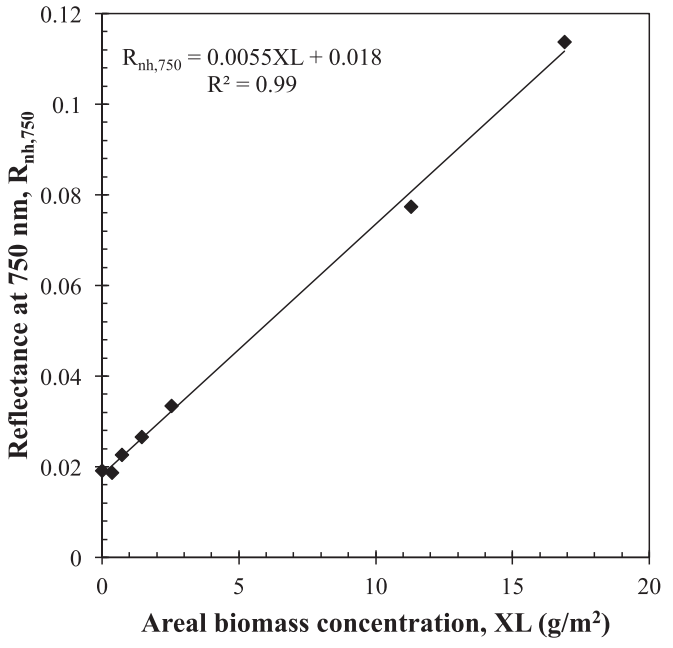

Fig. 5. Experimentally measured normal-hemispherical reflectance $R_{n h, 750}$ of the immobilized-cell films at $750 \mathrm{~nm}$ as a function of areal biomass concentration $X L$ between 0 and $16.9 \mathrm{~g} / \mathrm{m}^{2}$ along with linear curve fit.

reflectance of agar film alone (i.e., $X L=0 \mathrm{~g} / \mathrm{m}^{2}$ ) equal to $0.018 \pm$ 0.0024 . The latter was in good agreement with the normal-normal reflectance $\rho_{1,750}$ of 0.02 at the air/agar interface estimated by Eq. (7) using $n_{m, 750}$ of PBS. The results suggest that measurements of normal-hemispherical reflectance $R_{n h, 750}$ can be used to remotely and non-invasively estimate the areal biomass concentration $X L$ of immobilized-cell films in real time. Note, however, that the presence of excessive number of dead cells and/or contaminants in the culture may lead to inaccurate estimates of the areal biomass concentration $X L$.

\subsection{Agar film radiation characteristics}

Figs. $6 \mathrm{a}$ and $6 \mathrm{~b}$ show the spectral absorption $\kappa_{a, \lambda}$ and transport scattering $\sigma_{s, t r a, \lambda}$ coefficient of the agar gel retrieved from the normal-hemispherical transmittance $T_{n h, \lambda}$ and reflectance $R_{n h, \lambda}$ between 350 and $750 \mathrm{~nm}$. It indicates that the absorption coefficient $\kappa_{a, \lambda}$ of the agar gel was relatively constant around $30-40 \mathrm{~m}^{-1}$ for the wavelength range of interest. Absorption can be attributed to the fact that bacteriological grade A agar, used in this study, typically has an ash content of approximately 5-6 wt.\% [50] in the form of impurities composed of metals such as $\mathrm{Cu}, \mathrm{Mn}, \mathrm{Fe}, \mathrm{Al}, \mathrm{Cr}$, $\mathrm{Cd}, \mathrm{Ni}, \mathrm{Zn}$, and $\mathrm{Sn}$ and salts found in seawater containing elements such as $\mathrm{Na}, \mathrm{Cl}, \mathrm{Ca}, \mathrm{P}, \mathrm{S}, \mathrm{K}$, and $\mathrm{N}$ [51].

On the other hand, the transport scattering coefficient $\sigma_{s, t r a, \lambda}$ increased exponentially with decreasing wavelength from approximately $6.7 \mathrm{~m}^{-1}$ at $750 \mathrm{~nm}$ to reach $179 \mathrm{~m}^{-1}$ at $350 \mathrm{~nm}$. The corresponding least-square fit yielded $\sigma_{s, t r, a, \lambda}=2660 e^{-0.008 \lambda}$ with $\lambda$ expressed in $\mathrm{nm}$ and $\mathrm{R}^{2}=0.99$. In fact, agar gels have a porous microstructure with a broad pore size distribution ranging from 100 to $600 \mathrm{~nm}$ [52] resulting in strong light scattering. Note also that mean agar pore size decreases and its size distribution narrows with increasing dry agar concentration in the gel [52,53]. This could reduce scattering but would also increase absorption. In addition, increasing dry agar concentration increases the gel mechanical strength [10]. However, it also increases its liquid state viscosity making mixing with the microalgae cells and casting the mixture into a film difficult.

Overall, these results establish that agar is an absorbing and scattering medium and its effects should be accounted for in modeling radiation transfer in immobilized-cell films. Note however, that absorption and scattering by immobilized microalgae at con-
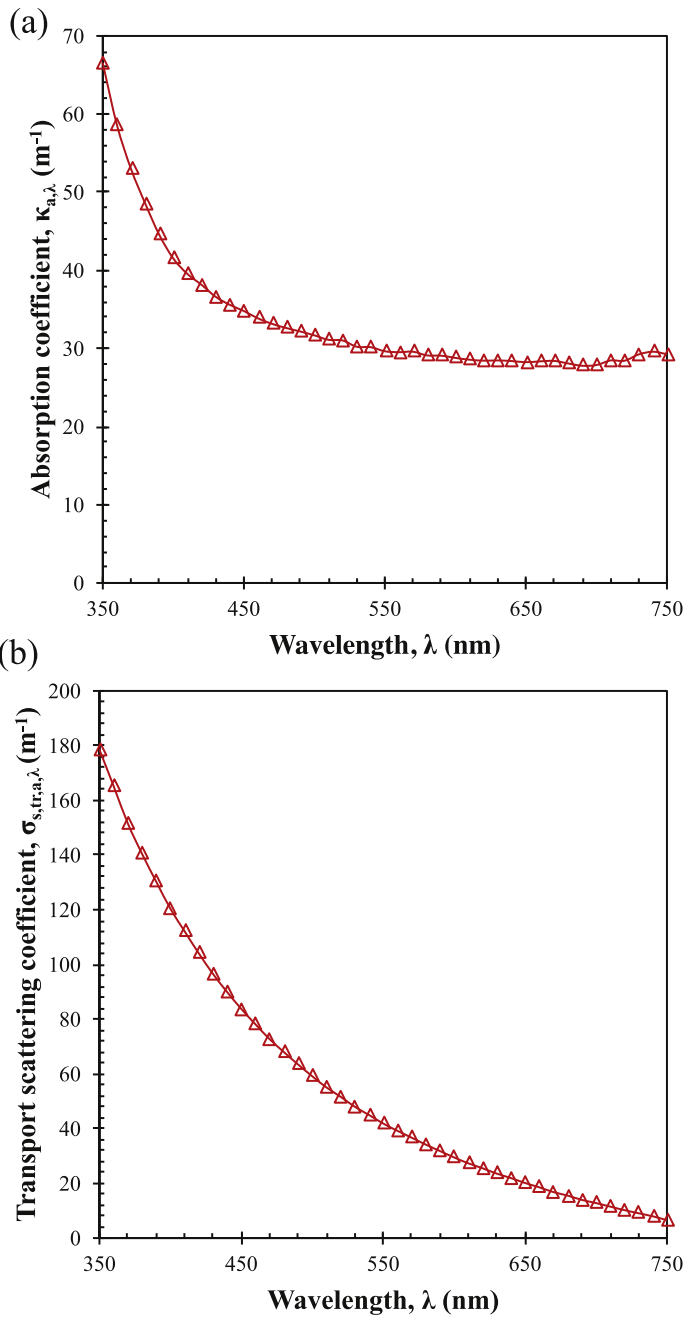

Fig. 6. Retrieved spectral (a) absorption $\kappa_{a, \lambda}$ and (b) transport scattering $\sigma_{s, t r a, \lambda}=$ $\left(1-g_{a, \lambda}\right) \sigma_{s, a, \lambda}$ coefficients of the $2.6 \mathrm{~mm}$ thick agar gel used for immobilizing the microalgae and containing 3.2 dry wt.\% of agar.

centration $X$ larger than $0.5 \mathrm{~kg} / \mathrm{m}^{3}$ still dominate over the contribution of agar gel between 350 and $700 \mathrm{~nm}$.

\subsection{Predicted transmittance and reflectance}

Figs. $7 \mathrm{a}$ to 71 compare the measured and predicted normalhemispherical transmittance $T_{n h, \lambda}$ and reflectance $R_{n h, \lambda}$ of immobilized P. kessleri films with areal biomass concentrations $X L$ equal to (a,b) 0.36, (c,d) 0.73, (e,f) 1.45, (g,h) 2.54, (i,j) 11.3, and (k,l) $16.9 \mathrm{~g} / \mathrm{m}^{2}$. Predictions of the transmittance $T_{n h, p r e d, \lambda}$ and reflectance $R_{n h, p r e d, \lambda}$ were based on the modified two-flux approximation given by Eqs. (10)-(12) based on the effective absorption $\kappa_{\lambda}$ and transport scattering $\sigma_{s, t r, \lambda}$ coefficients of the immobilized-cell films estimated according to Eqs. (17) and (18) using (i) the average spectral absorption $\bar{A}_{a b s, \lambda}$ and scattering $\bar{S}_{s c a, \lambda}$ cross-sections and the asymmetry factor $g_{\mu, 633}$ measured for the microalgae suspended in PBS (Figs. 3a to 3d) and (ii) the retrieved absorption $\kappa_{a, \lambda}$ and transport scattering $\sigma_{s, t r, a, \lambda}$ coefficients of the agar film with $X L=0 \mathrm{~g} / \mathrm{m}^{2}$ (Figs. 6a and 6b). Good overall agreement was observed between measurements and predictions of $T_{n h, \lambda}$ and $R_{n h, \lambda}$.

The modified two-flux approximation tended to underpredict the experimentally measured transmittance $T_{n h, \lambda}$ and to overpredict the experimentally measured reflectance $R_{n h, \lambda}$, particularly for large areal biomass concentrations $X L$. This can be attributed to (a) the assumption of constant microalgae asymmetry factor 
(a)

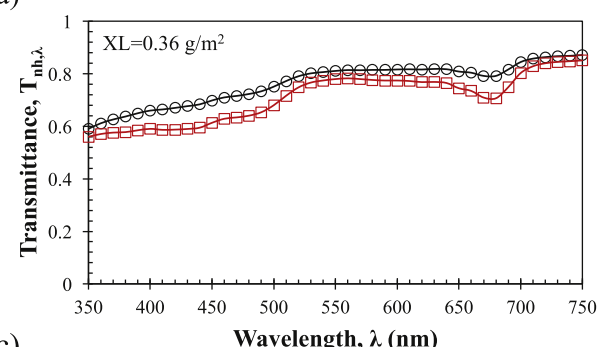

(c)

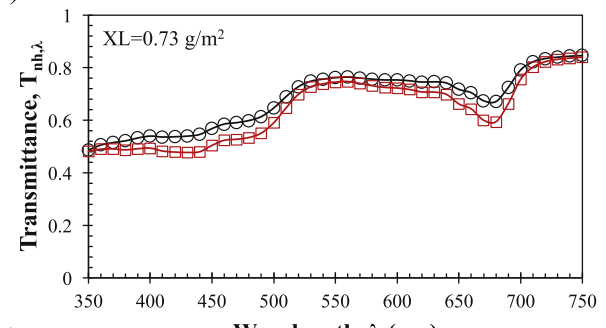

(e)

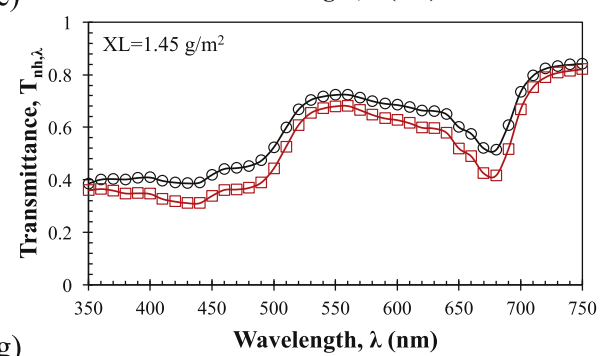

(g)

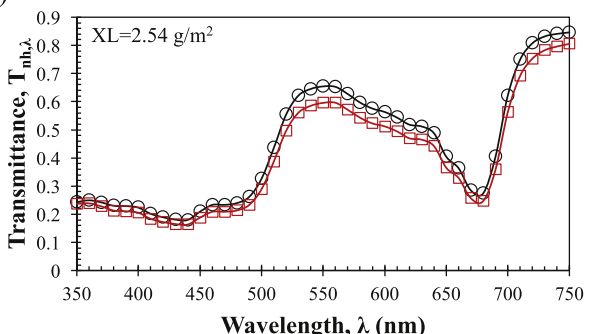

(i)

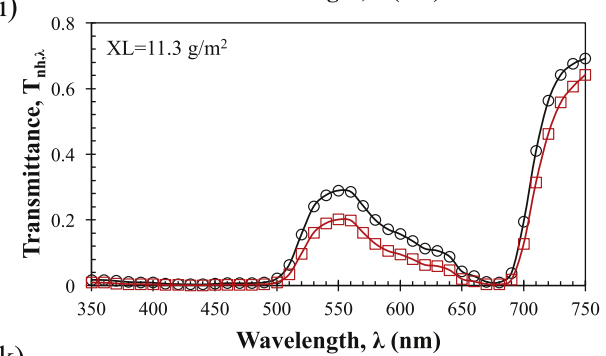

(k)

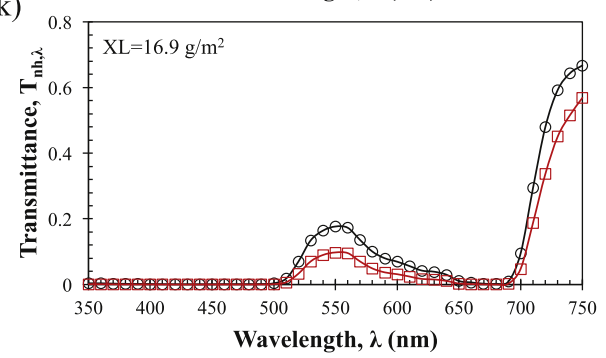

(b)
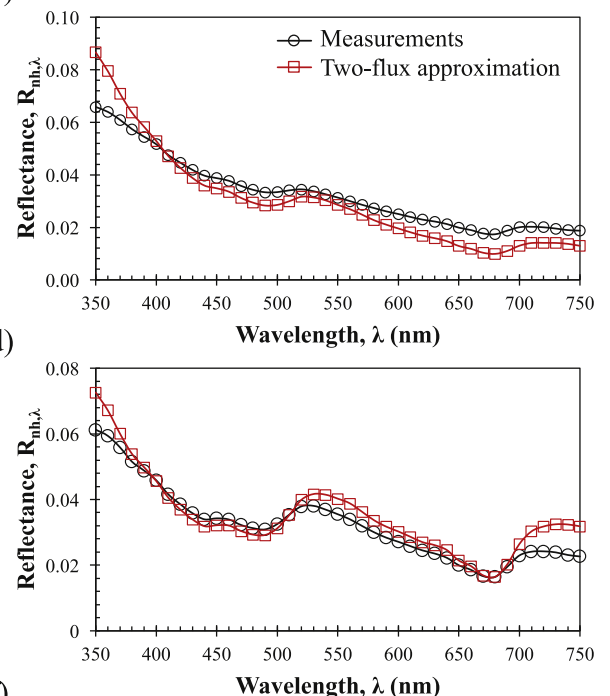

(f)

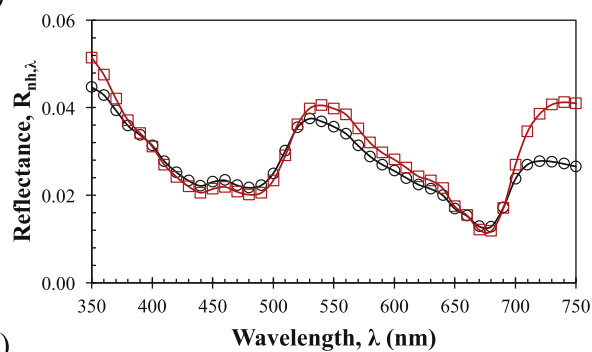

(h)

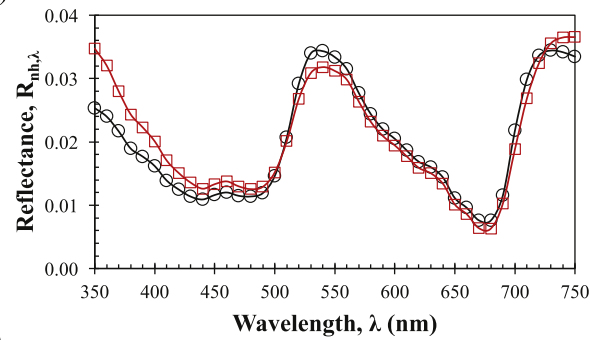

(j)

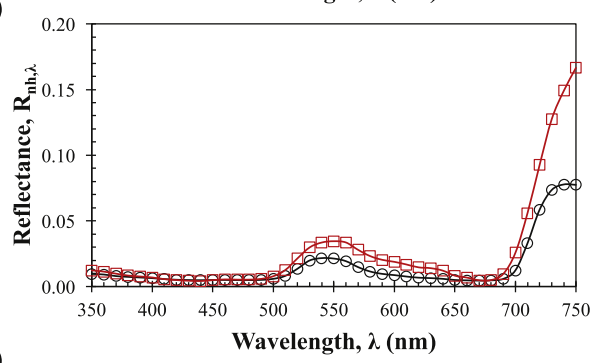

(1)

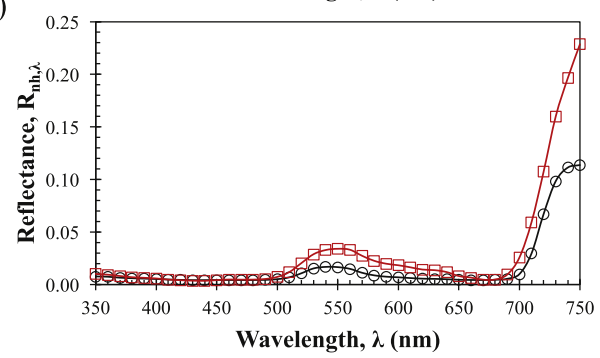

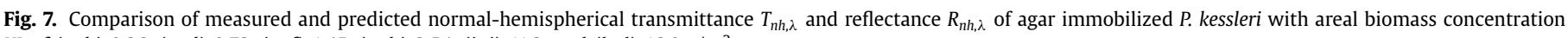
$X L$ of (a, b) 0.36, (c, d) 0.73, (e, f) 1.45, (g, h) 2.54, (i, j) 11.3, and (k, l) $16.9 \mathrm{~g} / \mathrm{m}^{2}$. 


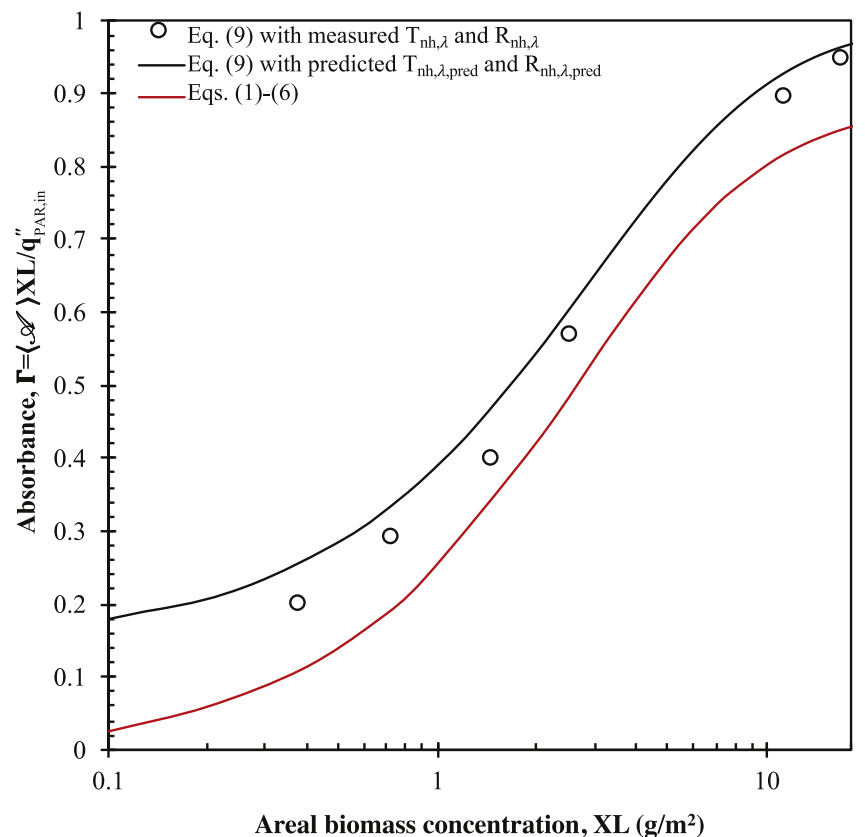

Fig. 8. Dimensionless mean rate of photon absorption $\Gamma=\left\langle\mathscr{A}_{\text {PAR }}\right\rangle X L / q_{\text {in }}^{\prime \prime}$ as a function of areal biomass concentration $X L$ estimated by (i) Eqs. (1)-(6) or (ii) by Eq. (9) using either the measured or (iii) the predicted normal-hemispherical transmittance $T_{n h, \lambda, \text { pred }}$ and reflectance $R_{n h, \lambda, \text { pred }}$.

$g_{\mu, \lambda}$ over the PAR region and more importantly (b) to the use of the transport approximation instead of a more accurate scattering phase function. Indeed, the transport approximation expresses the scattering phase function of the microorganisms as a sum of an isotropic component and a forward scattering peak at $\Theta=0^{\circ}$. By contrast the measured microalgae scattering phase function (Fig. 3a) features small values in the backward directions $\left(\Theta \geq 90^{\circ}\right)$ that are overestimated by the isotropic component of the transport approximation leading to the overprediction of the normalhemispherical reflectance $R_{n h, \lambda}$ particularly for $\lambda \geq 700 \mathrm{~nm}$ when the film is weakly absorbing.

\subsection{Mean rate of photon absorption}

Fig. 8 compares the dimensionless mean rate of photon absorption $\Gamma=\left\langle\mathscr{A}_{P A R}\right\rangle X L / q_{P A R, i n}$, as a function of the areal biomass concentration $X L$ estimated either (i) using the PAR-averaged mean rate of photon absorption estimated by Eqs. (1)-(6) or (ii) using Eq.- (9) based on the measured or (iii) on the predicted transmittance $T_{n h, \lambda, \text { pred }}$ and reflectance $R_{n h, \lambda, \text { pred }}$.

First, predictions of the PAR-averaged absorbance $\Gamma$ given by Eq. (9) using the experimentally measured or predicted normalhemispherical transmittance $T_{n h, \lambda}$ and reflectance $R_{n h, \lambda}$ fell within $10 \%$ of each other for areal biomass concentration $X L$ greater than $1 \mathrm{~g} / \mathrm{m}^{2}$. However, their relative difference increased up to $30 \%$ for $X L$ smaller than $1 \mathrm{~g} / \mathrm{m}^{2}$ due to the fact that the modified twoflux approximation underpredicted the experimentally measured normal-hemispherical transmittance $T_{n h, \lambda}$. The difference between the two approaches was not as significant at larger $X L$, as $T_{n h, \lambda}$ and $R_{n h, \lambda}$ tended to zero.

Moreover, Fig. 8 indicates that predictions of $\left\langle\mathscr{A}_{P A R}\right\rangle X L / q_{P A R \text {, in }}$ using Eqs. (1)-(6) were systematically smaller than those estimated using Eq (9). This was due to the fact that Eq. (9) implicitly accounted for absorption and scattering by both the microalgae and the agar gel (see Supplemental Material). By contrast, Eqs. (1)-(6) consider absorption and scattering by microalgae and agar when predicting the local fluence rate $G_{\lambda}(z)$ but only take into account absorption by microalgae when predicting the mean rate of photon absorption $\left\langle\mathscr{A}_{\mathrm{PAR}}\right\rangle$. In other words, Eq. (9) predict the mean rate of photon absorption of the ensemble of agar and microalgae while Eqs. (1)-(6) estimate only that of the microorganisms. The latter is the parameter that should be used when modeling the kinetics of microalgae since only photons absorbed by microalgae can participate in the biochemical reactions within the cell. Here also, the difference between the two approaches was apparent and most significant at very low microalgae concentrations $X L<<1 \mathrm{~g} / \mathrm{m}^{2}$ when the MRPA $\left\langle\mathscr{A}_{\text {PAR }}\right\rangle$ converges to zero. Therefore, the MRPA $\left\langle\mathscr{A}_{\text {PAR }}\right\rangle$ in immobilized-cell films should be predicted using Eqs. (1)-(6).

\subsection{Optimal areal biomass concentration}

As previously discussed, in order to maximize secondary metabolite productivity of immobilized-cell film PBRs exposed to normally incident solar radiation on the front face, the biomass concentration $X$ and the film thickness $L$ should be selected such that the local rate of photon absorption $\mathscr{A}_{P A R}(L)$ on the film backside is equal to the photosynthetic compensation point $\mathscr{A}_{C}$ [16,17,38,39].

Figs. 9a and 9b show (a) the optimum PAR-averaged fluence rate $G_{P A R}(z)$ estimated by Eqs. (5) and (6) and (b) the corresponding optimum RPA $\mathscr{A}_{\text {PAR }}(z)$ predicted by Eq. (3) for immobilized $P$. kessleri film exposed to an intermediate value of PAR-averaged incident solar irradiance $q_{P A R, \text { in }}^{\prime \prime}=200 \mu \mathrm{mol}_{h v} / \mathrm{m}^{2}$.s. Here, the optimum areal biomass concentration $(X L)_{\text {opt }}$ was $15.2 \mathrm{~g} / \mathrm{m}^{2}\left(5.85 \mathrm{~kg} / \mathrm{m}^{3}\right)$ and such that $\mathscr{A}_{\text {PAR }}(L)=\mathscr{A}_{C}=1,500 \mu \mathrm{mol}_{h v} / \mathrm{kg}$.s. Note that the latter corresponded to the photosynthetic compensation point of $C$. vulgaris but it was used in this study due to a lack of data for $P$. kessleri and because both species were green microalgae of the same family and size.

Furthermore, Figs. 9c and 9d show the (c) optimal biomass $X_{o p t}$ and (d) optimal areal biomass $(X L)_{o p t}$ concentrations of immobilized $P$. kessleri films as functions of incident photon flux density $q_{P A R, \text { in }}^{\prime \prime}$ ranging from 50 to $1,500 \mu \mathrm{mol}_{h v} / \mathrm{m}^{2} \cdot \mathrm{s}$ and for three different values of film thickness $L$ of $2.6,5$, and $10 \mathrm{~mm}$. Fig. 9c also shows the fitting curves of the form of $X_{\text {opt }}=c_{1} \ln \left(q_{\text {PAR,in }}^{\prime \prime}\right)+$ $c_{2}$ where $c_{1}$ and $c_{2}$ are constants estimated by the least square method for each film thickness considered. First, Fig. 9c indicates that the optimum biomass concentration $X_{\text {opt }}$ decreased with increasing film thickness $L$ for the same incident photon flux density $q_{P A R, i n}^{\prime \prime}$. However, Fig. 9 establishes that the optimum values of $X L$ were independent of the film thickness $L$. Instead, the product $X L$, representing the film optical thickness, determined the PBR performance. This was also observed for conventional PBRs (open ponds, flat-plate, and tubular) in both batch and continuous modes [30].

Fig. 9d also illustrates that the optimum areal biomass concentration $(X L)_{o p t}$ increased with increasing $q_{P A R, i n}^{\prime \prime}$. Increasing $X L$ beyond $(X L)_{\text {opt }}$ would result in the presence of a so-called "dark zone" where the respiration rate of the microorganisms is larger than the photosynthesis rate. This would result in loss of biomass and/or metabolite productivity. On the other hand, $X L<(X L)_{\text {opt }}$ would lead to a larger than optimum $\mathscr{A}_{\text {PAR }}(z)$ causing excessive dissipation of the absorbed energy by the microorganisms in the form of heat and fluorescence thus lowering metabolite productivity and PBR efficiency [54].

Moreover, the relationship between $(X L)_{o p t}$ and $q_{P A R, \text { in }}^{\prime \prime}$ can be fitted as

$(X L)_{\text {opt }}=6.44 \ln \left(q_{\text {PAR,in }}^{\prime \prime}\right)-18.51$

with coefficient of determination $R^{2}=0.99$. The mathematical form of this correlation can be derived from Eqs. (1)-(6) assuming (i) 
(a)
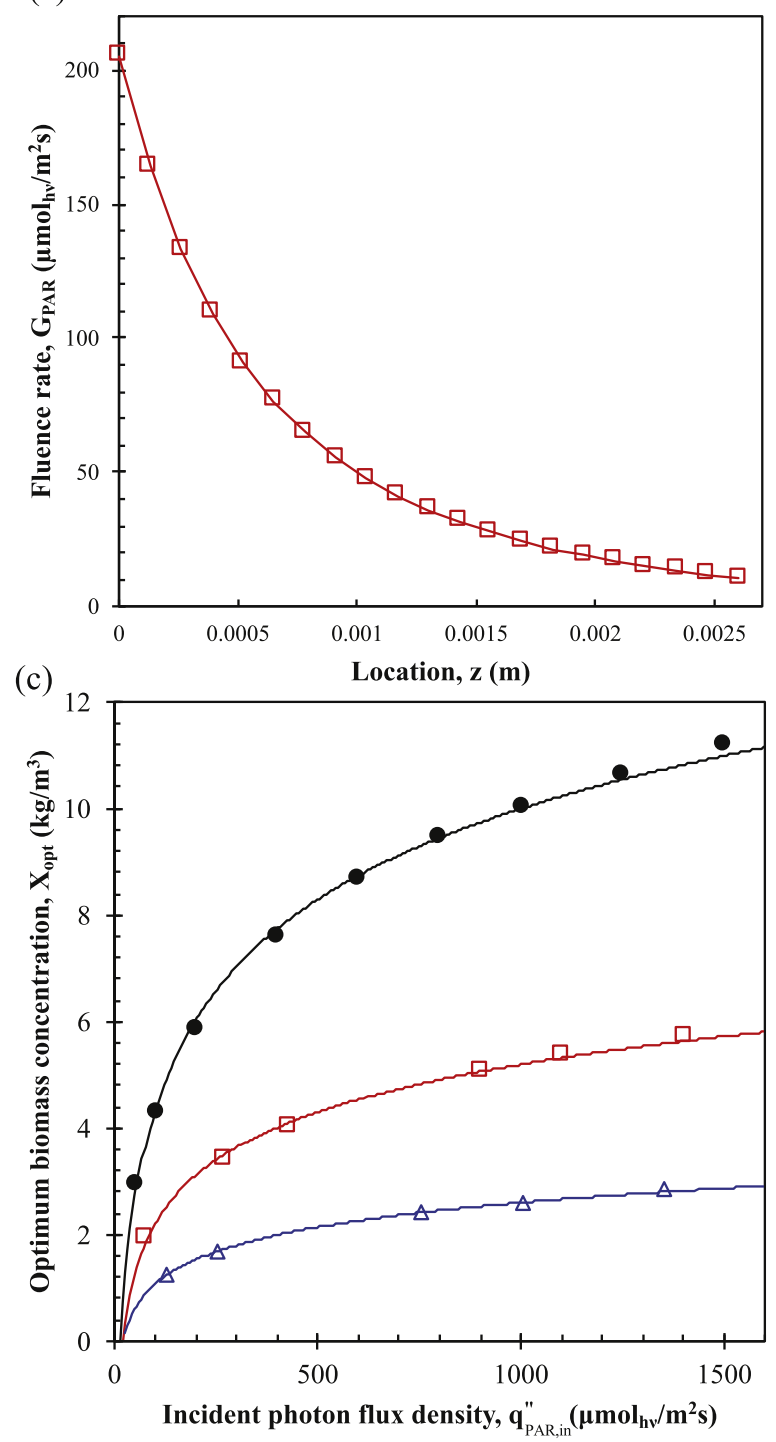

(b)

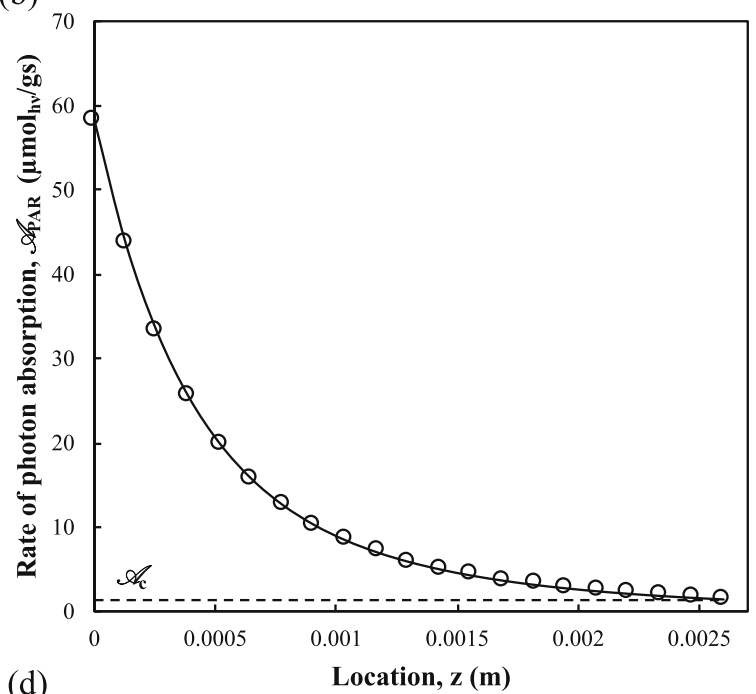

(d)

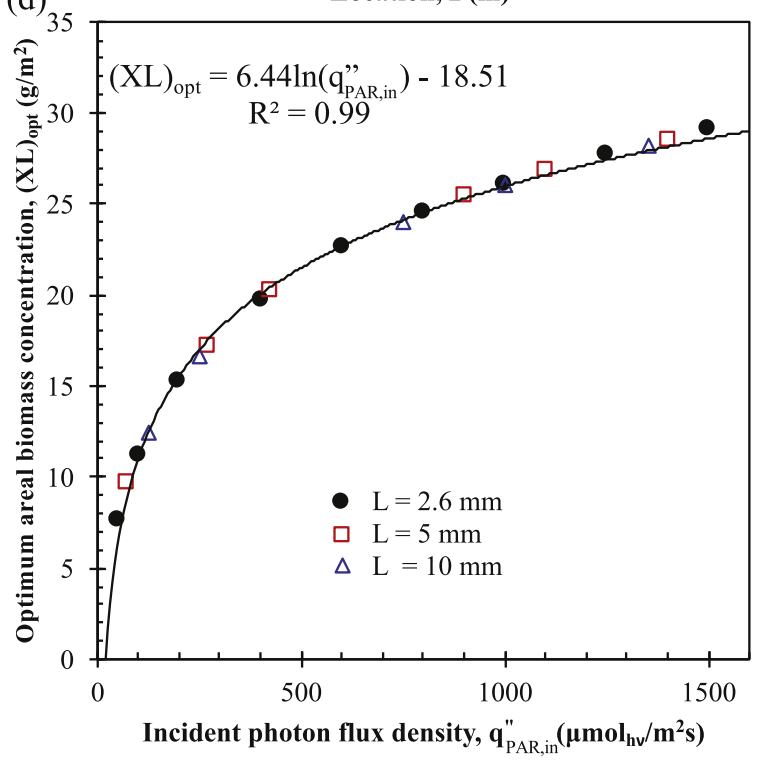

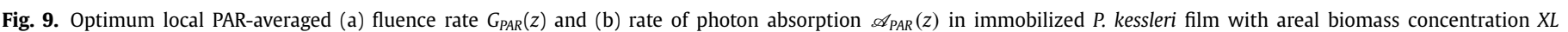

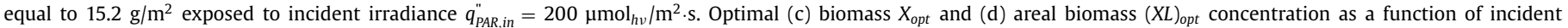
photon flux density $q_{P A R, \text { in }}^{\prime \prime}$ for film thickness $L$ of $2.6 \mathrm{~mm}, 5 \mathrm{~mm}$, and $10 \mathrm{~mm}$.

monochromatic incident photon flux density or grey film PBR and (ii) negligibly small backward scattering ratio $\left(b_{\lambda}=0\right)$. It is important to note that this design rule is valid for $P$. kessleri with the radiation characteristics reported in Fig. 3 for any film thickness $L$.

Finally, we assumed that the culture is only light-limited with no mineral limitation or oxygen inhibition. While this can be achieved in properly operated open-ponds and closed PBRs containing suspended microalgae, it must be validated for immobilized-cell film PBRs as the presence of agar gel may also lead to nutrient limitations. However, this falls outside the scope of the present study.

\section{Conclusion}

This paper developed and experimentally validated a model based on the modified two-flux approximation to predict light transfer in immobilized-cell PBRs. This was demonstrated successfully using Parachlorella kessleri cells immobilized in agar gel with areal biomass concentration $X L$ ranging from 0.36 to $16.9 \mathrm{~g} / \mathrm{m}^{2}$ ( $X$ between 0.145 and $6.49 \mathrm{~kg} / \mathrm{m}^{3}$ ). The absorption and transport scattering coefficients of the microalgae cells and the agar gel were measured independently. Then, the absorption and scattering coefficients of the immobilized-cell films were expressed as the sum of the respective contributions of their constituents. Predictions of the normal-hemispherical transmittance and reflectance of the immobilized-cell films by the two-flux approximation agreed well with the experimental measurements for all biomass concentrations considered. The results also suggest that normal-hemispherical reflectance at $750 \mathrm{~nm}$ could be used for real-time remote monitoring of the areal biomass concentration of immobilized-cell films. Finally, the optimum areal biomass concentration $(X L)_{\text {opt }}$ was estimated as a function of incident irradiance $q_{P A R, \text { in }}$ and was found to (i) be independent of film thickness $L$ and (ii) increase logarithmically with increasing $q_{P A R, \text { in }}^{\prime \prime}$ in light-limited cultures. 


\section{Acknowledgments}

This study was supported by the region Pays de la Loire, France through the project Atlantique Microalgae (AMI). L.P. thanks the Région Pays de la Loire for the Research Chair for International Junior Scientists.

\section{Supplementary material}

Supplementary material associated with this article can be found, in the online version, at 10.1016/j.jqsrt.2017.04.027

\section{References}

[1] Saha S, McHugh E, Murray P, Walsh D. Microalgae as a source of nutraceuticals. In: Phycotoxins: chemistry and biochemistry; 2016. p. 255-91.

[2] Wang H-M D, Chen C-C, Huynh P, Chang J-S. Exploring the potential of using algae in cosmetics. Biores Technol 2015;184:355-62. doi:10.1016/j.biortech.2014.12.001. http://www.sciencedirect.com/science article/pii/S0960852414017350.

[3] Yan N, Fan C, Chen Y, Hu Z. The potential for microalgae as bioreactors to produce pharmaceuticals. Int J Mol Sci 2016:17(6):962.

[4] Quinn J, Davis R. The potentials and challenges of algae based biofuels: a review of the techno-economic, life cycle, and resource assessment modeling. Biores Technol 2015;184:444-52. doi:10.1016/j.biortech.2014.10.075. http: //www.sciencedirect.com/science/article/pii/S0960852414014977.

[5] Griffiths M, Harrison S, Smit M, Maharajh D. Major commercial products from micro- and macroalgae. In: Bux F, Chisti Y, editors. Algae biotechnology: products and processes. Berlin, Germany: Springer; 2016. p. 269-300. ISBN 978-3319-12334-9. doi:10.1007/978-3-319-12334-9_14.

[6] Caporgno M, Taleb A, Olkiewicz M, Font J, Pruvost J, Legrand J, et al. Microalgae cultivation in urban wastewater: nutrient removal and biomass production for biodiesel and methane. Algal Res 2015;10:232-9. doi:10.1016/j.algal.2015. 05.011. http://www.sciencedirect.com/science/article/pii/S2211926415001319.

[7] Vigani M, Parisi C, guez Cerezo ER, Barbosa M, Sijtsma L, Ploeg M, et al. Food and feed products from microalgae: market opportunities and challenges for the EU. Trends Food Sci Technol 2015;42(1):81-92. doi:10.1016/j.tifs.2014.12. 004. http://www.sciencedirect.com/science/article/pii/S0924224414002787.

[8] Chisti Y. Large-scale production of algal biomass: raceway ponds. In: Bux F, Chisti Y, editors. Algae biotechnology: products and processes. Berlin, Germany: Springer; 2016. p. 21-40. ISBN 978-3-319-12334-9. doi:10.1007/ 978-3-319-12334-9_2.

[9] Travieso L, Benitez F, Dupeiron R. Sewage treatment using immobilized microalgae. Biores Technol 1992;40(2):183-7. doi:10.1016/0960-8524(92) 90207-E. http://www.sciencedirect.com/science/article/pii/096085249290207E.

[10] de Bashan L, Bashan Y. Immobilized microalgae for removing pollutants: review of practical aspects. Biores Technol 2010;101(6):1611-27. doi:10. 1016/j.biortech.2009.09.043. http://www.sciencedirect.com/science/article/pii/ S0960852409012498.

[11] Lebeau T, Moan R, Turpin V, Robert J-M. Alginate-entrapped Haslea ostrearia as inoculum for the greening of oysters. Biotechnol Tech 1998;12(11):847-50. doi:10.1023/A:1008885222634

[12] Lebeau T, Junter G-A, Jouenne T, Robert J-M. Marennine production by agar-entrapped Haslea ostrearia Simonsen. Biores Technol 1999;67(1):13-17. doi:10.1016/S0960-8524(99)00096-6. http://www.sciencedirect.com/science/ article/pii/S0960852499000966.

[13] Covarrubias S, de Bashan L, Moreno M, Bashan Y. Alginate beads provide a beneficial physical barrier against native microorganisms in wastewater treated with immobilized bacteria and microalgae. Appl Microbiol Biotechnol 2012;93(6):2669-80. doi:10.1007/s00253-011-3585-8.

[14] Jin J, Dupré C, Yoneda K, Watanabe MM, Legrand J, Grizeau D. Characteristics of extracellular hydrocarbon-rich microalga Botryococcus braunii for biofuels production: recent advances and opportunities. Process Biochem 2015;51:1866-75. doi:10.1016/j.procbio.2015.11.026. http://www.sciencedirect. com/science/article/pii/S1359511315301392.

[15] Gastineau R, Turcotte F, Pouvreau J-B, Moranais M, Fleurence J, Windarto E, et al. Marennine, promising blue pigments from a widespread Haslea diatom species complex. Mar Drugs 2014;12(6):3161-89. doi:10.3390/md12063161. http://www.mdpi.com/1660-3397/12/6/3161.

[16] Takache H, Christophe G, Cornet J-F, Pruvost J. Experimental and theoretical assessment of maximum productivities for the microalgae Chlamydomonas reinhardtii in two different geometries of photobioreactors. Biotechnol Prog 2010;26(2):431-40.

[17] Takache H, Pruvost J, Cornet J-F. Kinetic modeling of the photosynthetic growth of Chlamydomonas reinhardtii in a photobioreactor. Biotechnol Prog 2012;28(3):681-92.

[18] Pruvost J, Vooren GV, Cogne G, Legrand J. Investigation of biomass and lipids production with Neochloris oleoabundans in photobioreactor. Biores Technol 2009;100(23):5988-95.

[19] Pruvost J, Cornet J. Knowledge models for the engineering and optimization of photobioreactors. In: Posten C, Walter C, editors. Microalgal biotechnology: potential and production. Berlin, Germany: De Gruyter; 2012. p. 181-224.
[20] Kandilian R, Pruvost J, Legrand J, Pilon L. Influence of light absorption rate by Nannochloropsis oculata on triglyceride production during nitrogen starvation. Biores Technol 2014;163:308-19.

[21] Kandilian R, Tsao T-C, Pilon L. Control of incident irradiance on a batch operated flat-plate photobioreactor. Chem Eng Sci 2014;119:99-108.

[22] Pruvost J, Cornet J-F, Pilon L. Large-scale production of algal biomass: photobioreactors. In: Bux F, Chisti Y, editors. Algae biotechnology: products and processes. Netherlands: Springer; 2016. p. 41-66. ISBN 978-3-319-12334-9. doi:10.1007/978-3-319-12334-9_3.

[23] Pilon L, Berberoğlu H, Kandilian R. Radiation transfer in photobiological carbon dioxide fixation and fuel production by microalgae. J Quant Spectrosc Radiat Transfer 2011;112(17):2639-60.

[24] Dauchet J, Blanco S, Cornet J-F, Fournier R. Calculation of the radiative properties of photosynthetic microorganisms. J Quant Spectrosc Radiat Transfer 2015;161:60-84. doi:10.1016/j.jqsrt.2015.03.025. http://www.sciencedirect. com/science/article/pii/S0022407315001272.

[25] Pilon L, Kandilian R. Interaction between light and photosynthetic microorganisms. In: Legrand J, editor. Photobioreaction engineering, 48. Cambridge, MA: Academic Press; 2016. p. 107-49.

[26] Kandilian R, Lee E, Pilon L. Radiation and optical properties of Nannochloropsis oculata grown under different irradiances and spectra. Biores Technol 2013;137:63-73.

[27] Pottier L, Pruvost J, Deremetz J, Cornet J-F, Legrand J, Dussap C. A fully predictive model for one-dimensional light attenuation by Chlamydomonas reinhardtii in a torous photobioreactor. Biotechnol Bioeng 2005;91:569-82.

[28] Berberoğlu H, Yin J, Pilon L. Light transfer in bubble sparged photobioreactors for $\mathrm{H}_{2}$ production and $\mathrm{CO}_{2}$ mitigation. Int J Hydrogen Energy 2007; 32(13):2273-85.

[29] Berberoğlu H, Pilon L. Maximizing solar to $\mathrm{H}_{2}$ energy conversion efficiency of outdoor photobioreactors using mixed cultures. Int J Hydrogen Energy 2010:35:500-10.

[30] Lee E, Pruvost J, He X, Ramakanth R, Pilon L. Design tool and guidelines for outdoor photobioreactors. Chem Eng Sci 2014;106:18-29.

[31] Kong B, Vigil RD. Simulation of photosynthetically active radiation distribution in algal photobioreactors using a multidimensional spectral radiation model. Biores Technol 2014;158:141-8. doi:10.1016/j.biortech.2014.01.052. http://www.sciencedirect.com/science/article/pii/S0960852414000777.

[32] Kandilian R, Pruvost J, Artu A, Lemasson C, Legrand J, Pilon L. Comparison of experimentally and theoretically determined radiation characteristics of photosynthetic microorganisms. J Quant Spectrosc Radiat Transfer 2016;175:30-45.

[33] Kandilian R, Soulies A, Pruvost J, Rousseau B, Legrand J, Pilon L. Simple method for measuring the spectral absorption cross-section of microalgae. Chem Eng Sci 2016;146:357-68

[34] Cornet J-F, Dussap C, Dubertret G. A structured model for simulation of cultures of the cyanobacterium Spirulina platensis in photobioreactors: I. Coupling between light transfer and growth kinetics. Biotechnol Bioeng 1992;40:817-25.

[35] Jonasz M, Fournier G. Light scattering by particles in water: theoretical and experimental foundations. San Diego, CA: Academic Press; 2007. ISBN 9780123887511

[36] Dombrovsky L, Randrianalisoa J, Baillis D, Pilon L. Use of Mie theory to analyze experimental data to identify infrared properties of fused quartz containing bubbles. Appl Opt 2005;44(33):7021-31.

[37] Pruvost J, Cornet J-F, Legrand J. Hydrodynamics influence on light conversion in photobioreactors: an energetically consistent analysis. Chem Eng Sci 2008;63:3679-94.

[38] Cornet J, Dussap C. A simple and reliable formula for assessment of maximum volumetric productivities in photobioreactors. Biotechnol Prog 2009;25:424-35.

[39] Soulies A, Legrand J, Marec H, Pruvost J, Castelain C, Burghelea T, et al. Investigation and modeling of the effects of light spectrum and incident angle on the growth of Chlorella vulgaris in photobioreactors. Biotechnol Prog 2016;32(2):247-61. doi:10.1002/btpr.2244.

[40] Modest M. Radiative heat transfer. third. Oxford, UK: Elsevier; 2013.

[41] Ritchie R. Consistent sets of spectrophotometric chlorophyll equations for acetone, methanol and ethanol solvents. Photosynth Res 2006;89(1):27-41.

[42] Strickland J, Parsons T. A practical handbook of seawater analysis: pigment analysis. Bulletin of fisheries research board of canada. Fisheries Research Board of Canada; 1968.

[43] Berberoğlu H, Pilon L, Melis A. Radiation characteristics of Chlamydomonas reinhardtii $\mathrm{CC} 125$ and its truncated chlorophyll antenna transformants tla1, tlaX, and tla1-CW+. Int J Hydrogen Energy 2008;33(22):6467-83.

[44] Hulst HVD. Light scattering by small particles. New York, NY: Wiley; 1957.

[45] Moreno-Garrido I. Microalgae immobilization: current techniques and uses. Biores Technol 2008;99(10):3949-64. doi:10.1016/j.biortech.2007.05.040. http: //www.sciencedirect.com/science/article/pii/S0960852407004567.

[46] Press W, Teukolsky SA, Vetterling WT, Flannery BP. Numerical recipes: the Art of scientific computing. New York, NY: Cambridge University Press; 2007.

[47] Zhernovaya O, Sydoruk O, Tuchin V, Douplik A. The refractive index of human hemoglobin in the visible range. Phys Med Biol 2011;56(13):4013-21.

[48] Souliés A, Pruvost J, Legrand J, Castelain C, Burghelea T. Rheological properties of suspensions of the green microalga Chlorella vulgaris at various volume fractions. Rheol Acta 2013;52(6):589-605. doi:10.1007/s00397-013-0700-z.

[49] Bidigare RR, Ondrusek MEE, Morrow JHH, Kiefer DAA. In-vivo absorption properties of algal pigments. Proceedings of the SPIE 1990;1302:290-302.

[50] Agar product information sheet. http://www.sigmaaldrich.com/content/dam/ sigma-aldrich/docs/Sigma/Product_Information_Sheet/a4550pis.pdf. 
[51] Scholten H, Pierik R. Agar as a gelling agent: chemical and physical analysis. Plant Cell Rep 1998;17(3):230-5.

[52] Pernodet N, Maaloum M, Tinland B. Pore size of agarose gels by atomic force microscopy. Electrophoresis 1997;18(1):55-8. doi:10.1002/elps.1150180111.

[53] Narayanan J, Xiong J-Y, Liu X-Y. Determination of agarose gel pore size: absorbance measurements vis a vis other techniques. J Phys 2006;28(1):83-6 http://stacks.iop.org/1742-6596/28/i=1/a=017
[54] Pruvost J, Gouic BL, Lepine O, Legrand J, Borgne FL. Microalgae culture in building-integrated photobioreactors: biomass production modelling and energetic analysis. Chem Eng J 2016;284:850-61. doi:10.1016/j.cej.2015.08.118. http://www.sciencedirect.com/science/article/pii/S1385894715012012. 